\title{
Determinantes geográfico-políticos de la acción violenta guerrillera: un análisis de la concurrencia regional de guerrillas y paramilitares en el conflicto colombiano
}

\author{
Geographical-political determinants of guerrilla violent actions: \\ An analysis of the spatial concurrence of guerrillas and paramilitaries \\ in the Colombian conflict
}

\author{
JERÓNIMO RÍOS \\ Universidad EAN (Colombia)
}

\section{Cómo citar/Citation}

Ríos, J. (2017). Determinantes geográfico-políticos de la acción violenta guerrillera: un análisis de la concurrencia regional de guerrillas y paramilitares en el conflicto colombiano. Revista Española de Ciencia Política, 44, 121-149.

Doi: https://doi.org/10.21308/recp.44.05

\section{Resumen}

El análisis espacial de la violencia ha ganado peso específico en la investigación para la paz y la resolución de conflictos en los últimos años, lo cual ha permitido arrojar luz sobre cómo surgen los conflictos armados, cómo evolucionan y qué factores afectan a su transformación. En lo que respecta al caso colombiano en particular, tal posibilidad está por desarrollar y mayoritariamente se ha centrado en la relación espacial de los grupos armados con sus principales fuentes de financiación, desatendiendo distintas posibilidades como la disputa por el territorio frente a otros grupos armados o frente al Estado. Teniendo en cuenta este vacío en la literatura, se intenta dar aquí respuesta a un aspecto todavía por profundizar en el conflicto colombiano: ¿qué sucedió cuando paramilitares y guerrillas coincidieron en tiempo y lugar? La respuesta predominante atribuye al paramilitarismo una victoria allí donde disputó el poder local sobre las guerrillas. Sin embargo, tomando como referencia dos enclaves como son el noreste y el suroeste de Colombia, de notable arraigo de las Fuerzas Armadas Revolucionarias de Colombia (FARC) y del Ejército de Liberación Nacional (ELN), el artículo trata de refutar el supuesto efecto de expulsión que se atribuye al paramilitarismo. Ello se hace analizando los datos facilitados por el Observatorio de Derechos Humanos y Derecho Internacional Humanitario (ODHDIH) adscrito a la Vicepresidencia de la República, y examinando las dinámicas de 
activismo guerrillero que, precisamente, muestran que el paramilitarismo no resultó suficiente para expulsar a las guerrillas de sus enclaves de mayor arraigo y control.

Palabras clave: geografía política, violencia. conflicto armado colombiano, Ejército de Liberación Nacional, Fuerzas Armadas Revolucionarias de Colombia.

\begin{abstract}
The spatial analysis of violence has gained specific relevance in peace and conflict resolution research in recent years, what has shed light on how armed conflicts arise, how they evolve and what factors affect their transformation. Regarding the Colombian case more in particular, this possibility is still to be developed and has mainly focused on the spatial relationship of armed groups with their main sources of funding, disregarding different possibilities such as the dispute over territory with other armed groups or against the State. Taking into consideration this gap in the literature, this article addresses an aspect of the Colombian conflict that has been scarcely studied so far, namely, what happened when paramilitaries and guerrillas coincided in time and place? The predominant response attributed to paramilitarism a victory wherever it disputed the local power to the guerrilla. However, taking as a reference two enclaves such as the north-east and south-west of Colombia, where the Revolutionary Armed Forces of Colombia (FARC) and the National Liberation Army (ELN) are deeply rooted, the article tries to refute the alleged displacement effect attributed to paramilitarism. This is done by analyzing the data provided by the Observatory on Human Rights and International Humanitarian Law (ODHDIH) attached to the Vice-Presidency of the Republic, and examining the dynamics of guerrilla activism, which show how paramilitarism was not enough to displace the guerrillas from the tenclaves of their deepest roots and control.
\end{abstract}

Keywords: political geography, violence. colombian armed conflict, National Liberation Army, Revolutionary Armed Forces of Colombia.

\title{
INTRODUCCIÓN
}

El presente trabajo pudiera entenderse como una reivindicación de la geografía política como disciplina de análisis politológico para la comprensión de los conflictos armados y su particular evolución y desarrollo. Y es que, tradicionalmente, la investigación para la paz y la resolución de conflictos ha estado dominada por otro tipo de miradas y disciplinas dentro de las ciencias sociales, como por ejemplo la teoría de juegos, la estadística o los estudios militares, entre otros (Woodhouse et al., 2015). De este modo, la geografía ha sido una posibilidad de estudio de la violencia relegada hasta hace relativamente poco tiempo, si bien su imbricación con la investigación para la paz y la resolución de conflictos posibilita nuevos enfoques para la comprensión de cómo surgen los conflictos armados y los grupos guerrilleros, cuál es su arraigo y sus dinámicas de activismo, de qué modo se produce la interacción con la fuerza pública o grupos menores y qué posibilidades presenta su superación. 
$\mathrm{Al}$ respecto, como se muestra en la revisión de la literatura científica, el recurso a la geografía como instrumento de análisis de la violencia ha sido utilizado en análisis de casos como la violencia política en Oriente Medio o en África Subsahariana, lo que ha permitido investigar qué factores concurren en el surgimiento de grupos guerrilleros o grupos terroristas e, igualmente, qué aspectos han ayudado a comprender su longevidad, su desaparición o la disputa por el poder entre grupos armados (Saleyhan, 2009; Linke et al., 2012; O'Loughlin, 2012; Basedau y Pierskalla, 2013; Linke y O'Loughlin, 2015). A tal respecto, América Latina ofrece numerosas posibilidades de comprensión de la violencia en términos espaciales, pues los trabajos desde la geografía política son todavía escasos si se comparan con los realizados desde otros enfoques.

Dentro del universo de conflictos armados acontecidos en América Latina, solo el colombiano se mantiene vigente si se exceptúan las facciones postsenderistas en Perú que siguen presentes, de manera muy minoritaria y residual, en las regiones de Huallaga y el valle de los ríos Apurímac, Ene y Mantaro. Así, el conflicto colombiano, además de resultar el más longevo del continente -formalmente, comienza en 1964se ha caracterizado por ser uno de los más complejos, a tenor no solo de la concurrencia de factores tales como el narcotráfico o la minería ilegal, sino por la yuxtaposición de guerrillas de primera generación -Fuerzas Armadas Revolucionarias de Colombia (FARC), Ejército de Liberación Nacional (ELN) y Ejército Popular de Liberación (EPL)-, guerrillas de segunda generación, propias de los setenta y los ochenta -Movimiento 19 de Abril (M19) o Guerrilla Indigenista Quintín Lame (GIQL)-, o cárteles de la droga y grupos paramilitares como las Autodefensas Unidas de Colombia (AUC).

Si bien, desde el 24 de noviembre de 2016 el conflicto con las FARC puede entenderse por finalizado, es igualmente cierto que persisten algunas disidencias que no se han desmovilizado, aparte de la guerrilla del ELN y los grupos postparamilitares que se disputan el poder territorial dejado por las FARC, de modo que pudiera entenderse el colombiano como el único conflicto armado, pese a todo, vigente en América Latina y reducto directo de la Guerra Fría.

Sobre el conflicto colombiano, de acuerdo con lo anterior, han primado los trabajos de cariz historiográfico, militar o, sobre todo, de análisis económico de los factores que produjeron el conflicto o que en su defecto lo hicieron evolucionar y perdurar por más de medio siglo. Sin embargo, como se verá después, los estudios espaciales quedan, en cierto modo, fuertemente focalizados en la relación de las diferentes estructuras guerrilleras con sus particulares fuentes de financiación, desatendiendo algunas otras situaciones como la confluencia de actores en tiempo y lugar y cómo evolucionó el conflicto cuando la violencia tuvo lugar bajo condiciones de disputa del poder y los recursos.

$\mathrm{Al}$ respecto, dentro de las diferentes posibilidades que un estudio espacial de la violencia permite en Colombia, parece necesario analizar una de las realidades menos profundizadas del conflicto armado interno: ¿qué sucedió cuando guerrillas y paramilitares coincidieron en tiempo y lugar? La falta de estudios geográficos al respecto ha tendido a atribuir, casi por automatismo, la victoria paramilitar en Colombia allí donde éste coincidió en espacio y tiempo con las guerrillas, de manera tal que la idea 
es tomar dos lugares de importante arraigo de FARC y ELN, como son el noreste colombiano, específicamente los departamentos de Arauca y Norte de Santander, y el suroeste, en torno a los departamentos de Valle del Cauca, Cauca, Nariño, Putumayo, Huila y Tolima, y observar si allí donde hubo coincidencia es plausible la afirmación de expulsión de las guerrillas por parte del paramilitarismo. El propósito último sería el de desmitificar esta atribución predominante en favor del paramilitarismo y comprobar la hipótesis de que el arraigo de las guerrillas colombianas se mantuvo inalterado en aquellos escenarios de mayor presencia, a pesar de la amenaza paramilitar.

Sobre la base de lo anterior, este trabajo trata de responder a la pregunta sobre qué paso en Colombia cuando las AUC, en su proceso de expansión, a inicios de la década pasada, buscan relegar en su posición territorial a las guerrillas de las FARC y ELN. Así, su resultado más importante sería el de mostrar cómo en los dos escenarios objeto de estudio -el noreste y el suroeste- no se apreciaría expulsión o debilitamiento directo de las FARC, mientras que, en el caso del ELN, tal vicisitud sería solo apreciable en el noreste, en tanto que se trata de su tradicional escenario de acción, pues su posición en el sur colombiano es apenas marginal. Para ello, se analiza el período que transcurre entre el surgimiento de las AUC, entre finales de 1997 e inicios de 1998, y su completa desmovilización, entre 2004 y principios de 2005, y tomando en consideración que estas dos regiones, durante este tiempo, no fueron prioridad para la política de seguridad democrática puesta en marcha por el entonces presidente, Álvaro Uribe Vélez (Ríos, 2017).

Dicho hallazgo contradiría a la posición predominante en la literatura que atribuye al paramilitarismo -asociado a masacres y desplazamiento forzado- la capacidad de haber hecho desaparecer a las guerrillas allí donde coincidió en tiempo y lugar (Trejos, 2016). De la misma manera, un trabajo de estas características conlleva algunas dificultades metodológicas fruto de operacionalizar un concepto tan intrincado y multifactorial como es el de violencia y que, para este caso, se reduce al número de acciones armadas unilaterales ${ }^{1}$ protagonizadas por las FARC y el ELN, por año y municipio. De este modo, se obvian elementos indisociables de la violencia, como la dimensión estructural, relacionada con las condiciones socioeconómicas del lugar, y los aspectos simbólico-afectivos que se relacionan con la violencia cultural (Galtung, 2003). Sea como fuere, por otro lado, recurrir, stricto sensu, a la violencia manifiesta ejercida por los grupos guerrilleros permite observar si, en su coincidencia con el despliegue paramilitar, hubo afectación alguna sobre los niveles de activismo y presencia.

Asimismo, una segunda complejidad, relacionada con la anterior, suele corresponderse con la fuente que sistematiza la información, pues los datos suelen provenir de fundaciones u observatorios de la sociedad civil. Sin embargo, en esta ocasión, los datos que son objeto de análisis en las siguientes páginas proceden de la fuente más confiable que existe sobre violencia directa en el conflicto colombiano: el Observatorio de Derechos Humanos y Derecho Internacional Humanitario, adscrito a la

1. Se entienden por acciones guerrilleras la suma de ataques contra la policía y ejército, hostigamientos, emboscadas, ataques a la población y otros eventos de terrorismo. 
Presidencia de la República (ODHDIH). Esta entidad permitió, expresamente, el acceso a su banco de datos y cartografías sobre acciones guerrilleras, las cuales se encuentran desglosadas municipalmente, desde el 1 de enero de 1998 hasta el 31 de diciembre de $2006^{2}$ y con una base de información que, en su momento, fue recopilada y sistematizada por el Departamento Administrativo de Seguridad.

Finalmente, del lado de la presencia paramilitar se recurriría a la ubicación espacial de los diferentes grupos paramilitares vinculados a la estructura de las AUC, de acuerdo a la información cartográfica facilitada por el Centro Nacional de Memoria Histórica (CNMH) que, a través de su herramienta Rutas del Conflicto, pone a disposición una valiosa información sobre el alcance y la intensidad de la expansión territorial de cada bloque paramilitar.

Dicho de otro modo, y con el propósito de comprobar la hipótesis expuesta, de lo que se trataría en las siguientes páginas es de observar si la concurrencia de bloques paramilitares de las AUC con estructuras guerrilleras de las FARC y el ELN se traduce en reducciones o no en el nivel de activismo guerrillero. Así, en principio, lo que se presumiría es que en las dos regiones objeto de estudio, en tanto que son escenarios con un importante arraigo guerrillero, con sólidas fuentes de poder económico, mayormente provenientes del secuestro, la extorsión y el narcotráfico, y una condición geográfica periférica, fronteriza, y de marcada impronta selvática o montañosa, la derrota guerrillera frente al paramilitarismo es una hipótesis que, a tenor de los datos expuestos, difícilmente se puede aceptar.

El trabajo se organiza en cuatro partes diferenciadas. En primer lugar, tras esta introducción y algunas consideraciones metodológicas, se presenta un marco teórico que reivindica la importancia de la geografía política en su relación con la investigación para la paz y la resolución de conflictos y que, a su vez, revisa la literatura más destacada sobre la geografía de la violencia en Colombia. En tercer lugar, se describe la interacción de las guerrillas allí donde coincidieron, en tiempo y lugar, con las estructuras paramilitares de las AUC, haciendo un análisis pormenorizado del activismo armado de las FARC y el ELN en las regiones del noreste y del suroeste colombiano. Por último, se ofrecen algunas conclusiones planteando nuevos horizontes y escenarios que no agotan el objeto de estudio: conflicto armado en Colombia.

\section{LA GEOGRAFÍA POLÍTICA EN LA COMPRENSIÓN DE LA VIOLENCIA}

La geografía política, junto con las investigación para la paz y la resolución de conflictos, ha sido la disciplina que dentro de la ciencia política ha dado más importancia

2. El período de estudio comienza el 1 de enero de 1998 porque la estructura paramilitar colombiana de las AUC se conforma, tras la redefinición de las Autodefensas Campesinas de Córdoba y Urabá (ACCU) en el último trimestre de 1997. Asimismo, llega hasta el 31 de diciembre de 2006 porque todos los grupos paramilitares terminan por desmovilizarse entre finales de 2004 y finales 2005 . 
a los contextos espaciales en su intención por comprender ciertos fenómenos políticos como la violencia. De hecho, la propensión hacia los conflictos armados ha ganado peso específico mediante el estudio y la variación de intervalos espacio-tiempo en las categorías de análisis realizadas sobre la violencia. Así, en los últimos años, la geografía política se ha reivindicado como un campo prolífico para el estudio de la violencia en su relación causal con diferentes tipos de población (Raleigh y Hegre, 2009), de acuerdo a ciertas condiciones de pobreza (Hegre et al., 2011), atendiendo a dimensiones fronterizas (Buhaug y Rød, 2006), con base en la proximidad de recursos como gas y petróleo (Basedau y Pierskalla, 2013) o en atención a la relación entre violencia y la pluralidad étnica de una comunidad (McDoom, 2014).

Todo lo anterior, por entender que las condiciones demográficas, sociales o los elementos culturales, según su heterogeneidad, afectan particularmente a los contextos espaciales sobre los cuales tiene lugar la violencia, entendiendo que esta solo resulta comprensible a partir de entender la interacción de la población con el lugar. La intrincada y particular relación del individuo con el ambiente que le rodea construye el contexto espacial sobre el que la geografía política focaliza su interés disciplinario, interpretando el contexto como un escenario de interacciones en medio de diferentes elementos que, a su vez, conforman una totalidad. Escenario que, para Agnew (1987: 5), no es más que el producto de un día a día; de interacciones personales que desembocan en construcciones sociales (Pattie y Johnston, 2000), y que, a su vez, integra diferentes escalas geográficas, de lo local a lo global (Taylor y Flint, 2002).

A tal efecto, para la geografía política, como sostiene Agnew (1987: 60), la base fundamental explicativa de la violencia la determinan las particularidades de la localidad. Particularidades que son las únicas que pueden explicar por qué, bajo mismas circunstancias objetivas, unos escenarios tienden a ser más violentos que otros. De hecho, en los últimos años se ha incrementado sustancialmente el número de trabajos académicos que desde la Geografía Política buscan comprender los factores relacionados con la violencia. Por ejemplo, Linke et al.(2012) intentan aproximarse a explicar el caso de la violencia en Irak, mostrando de qué modo el ámbito territorial que define la dinámica acción/reacción social frente a la violencia cambia una vez que se controlan los términos espacio/temporales de la misma. Tanto que afecta directamente al modo en que, a través de la distancia y el tiempo, varía la relación del entorno social subnacional con las lógicas propias de la violencia. Algo similar plantean Linke y O'Loughlin (2015), cuando buscan entender las respuestas de violencia en el norte del Cáucaso, reconociendo que elementos particulares de la localidad, como el orgullo nacional, el capital social, el cariz separatista o la exposición directa a la violencia, son factores que determinan las respuestas y percepciones de la comunidad local. Sin embargo, esta afectación variaría en función de cómo se controlen las coordenadas espacio-temporales. Una conclusión que, en unos términos muy similares, se puede encontrar en el trabajo de Schutte y Donnay (2014), también sobre Irak.

Otros, como Forø y Buhaug (2015), sin restar valor a lo anterior, reivindican la importancia de la geografía física como contexto modulador de ciertos elementos políticos, igualmente presentes en el trabajo de Kaplan (2013). De este modo, escenarios 
geográficamente periféricos, de difícil accesibilidad y de mayor distancia con respecto de los centros económicos y políticos del país, operan como factor clave para comprender ciertas dinámicas de conflicto intraestatal, de acuerdo con Horowitz (1985) o Brancati (2006). Así, Forø y Bahaug (2015: 7) hacen valer, en la comprensión de la violencia, factores tales como la distancia con la ciudad, la disponibilidad de corredores y refugios selváticos o montañosos, además de la distancia sociocultural con los centros políticos y económicos del país (inaccessibility). Específicamente, se argumenta que el Estado permea en estos enclaves de una manera parcial, dada su marcada debilidad institucional, lo cual puede desvirtuar la noción clásica de autoridad y favorecer la emergencia de poderes paraestatales como guerrillas o fuerzas paramilitares, como sucede en el caso colombiano (Ríos, 2016). Es decir, factores tales como la fractura regional, la ausencia de infraestructura que facilite la conexión interterritorial, la afectación de fronteras inestables, así como la presencia de imaginarios distanciados en clave de unidad nacional constituirían una ventana de oportunidad para la emergencia de conflictos armados internos, tal y como plantean Salehyan (2009), Cunningham et al. (2009)) o Forø y Bahaug (2015).

Así, por ejemplo, en el planteamiento de este trabajo, centrado en dos enclaves periféricos de Colombia -tanto geográficos como socioeconómicos- se reivindicaría la misma hipótesis por la cual se presume que cuanta mayor es la distancia con los centros de poder político y económico en un país, mayor es la propensión a experimentar dinámicas de violencia por parte de grupos armados o guerrillas dentro de un conflicto interno ${ }^{3}$. De hecho, toda esta prolífica literatura iría en la misma lógica que aportes como los de Buhaug y Rød (2006), quienes consideran que las grandes distancias con el centro nacional son un factor clave en cuanto al riesgo interno de conflicto; O'Loughlin (2012), que apunta a que los conflictos internos tienden a una mayor fronterización, o Cederman et al. (2013), quienes señalan como un factor importante la construcción de comunidades étnicas trasnacionales que, desde la frontera, tienden a producir un lugar que dista de las dinámicas mononacionales del Estado.

Finalmente, una aportación reciente y en línea con lo anterior sería la de Schutte (2015: 1112), quien reivindica la geografía como disciplina de estudio sobre la violencia según dos argumentos: de un lado, destacando el valor agregado que las zonas periféricas han supuesto generalmente para poner en marcha procesos insurgentes, como muestran los casos de China, Cuba o Tailandia; de otro, precisando que a medida que la violencia descrita sea más periférica, las posibilidades de éxito del Estado en cuanto a una victoria militar se reducen muy sustancialmente, algo más difícil aún si sobre estos escenarios se consolidan fuentes de financiación (lootable resources) que permitan a los grupos armados obtener ingentes recursos económicos con los que sostener en el tiempo la duración de un conflicto armado (Snyder, 2006).

3. Según las fuentes del Departamento de Prosperidad Social (2015), la mayoría de los departamentos seleccionados, con la excepción de Valle del Cauca, presentan algunos de los peores niveles del país en términos de desarrollo humano, calidad de vida, necesidades básicas insatisfechas, PIB per cápita o tasa de desempleo. 
En lo que respecta a Colombia, varios trabajos se han servido de la geografía para atender y entender las evoluciones del conflicto armado. El primer intento por representar en un mapa lo que resultaba la magnitud de la violencia ${ }^{4}$ lo plantean Fals Borda et al., (1962), si bien de una manera muy rudimentaria, no solo por cuestiones tecnológicas, sino por la misma comprensión de violencia, entendida como cualquier acción que gravase la vida humana en dicho contexto de violencia. Hay que esperar tres décadas para encontrar un trabajo que, nuevamente, recupere la necesidad de presentar en mapas las configuraciones espaciales de la violencia en Colombia. Reyes (1993), en Geografia de la Guerra, representa la violencia guerrillera de las FARC, si bien con una intención poco alejada de la anterior, al mostrar en un mapa los municipios que, al menos, habían tenido una acción guerrillera en los últimos años, lo cual arroja como resultado un mapa casi en su totalidad monocolor negro. Igualmente, Vélez (2001) novedosamente busca comparar marcos temporales distintos, presentando cuál era la presencia guerrillera en 1980 y dos décadas después, aunque al trabajar sobre categorías 1-0 tampoco termina dando cuenta de la magnitud y la intensidad real del activismo guerrillero.

Lo anterior es superado por Echandía (1999) quien, en sus primeras representaciones cartográficas, trasciende del foco de magnitud generalizada de la violencia en Colombia para visibilizar aquellas regiones que se encuentran más afectadas mediante una gama de colores en función de la intensidad de las operaciones de la guerrilla. Aunque representa un avance en los estudios espaciales de la violencia, hasta hoy mantiene una debilidad casi irresoluta al utilizar el conjunto del municipio como la unidad de representación, lo cual provoca que buena parte del país aparezca sobrerrepresentada, especialmente la mitad sur, al concurrir municipios muy poco poblados, con violencia estrictamente focalizada en veredas rurales, pero extensiones superiores a los $40000 \mathrm{~km}^{2}$.

En otra línea, Reyes y Bejarano (1988) intentan visibilizar la ruralización real del conflicto armado colombiano y su cercana relación con las luchas agrarias del pasado, lo cual dista del trabajo de sus predecesores inmediatos, centrados en mostrar la cercana relación entre pobreza, ausencia del Estado y muertes violentas. Causas objetivas que, en esencia, eran consideradas como la matriz explicativa del desigual desarrollo de la violencia en el país. Esta circunstancia es abordada por Mesclier (1999), cuya mayor contribución es poner de manifiesto de qué modo los grupos armados tenían un especial arraigo sobre zonas de potencial económico y donde se desarrolla un asedio hacia los centros económicos y administrativos del país, observándose dos cinturones de violencia que aíslan al centro y que conforman zonas de ocupación y dominio de guerrillas, paramilitares y cárteles de la droga.

4. Contexto de guerra civil que acontece en Colombia, desde 1948 y hasta 1964, con motivo del asesinato del candidato liberal Jorge Eliécer Gaitán, el 9 de abril de 1948, lo cual sume al país en una tesitura de violencia desmedida a partir de las identidades partidarias, liberales y conservadoras, dejando más de 200000 muertes. 
MAPA 1.

REPRESENTACIONES CARTOGRÁFICAS DE LA VIOLENCIA EN COLOMBIA

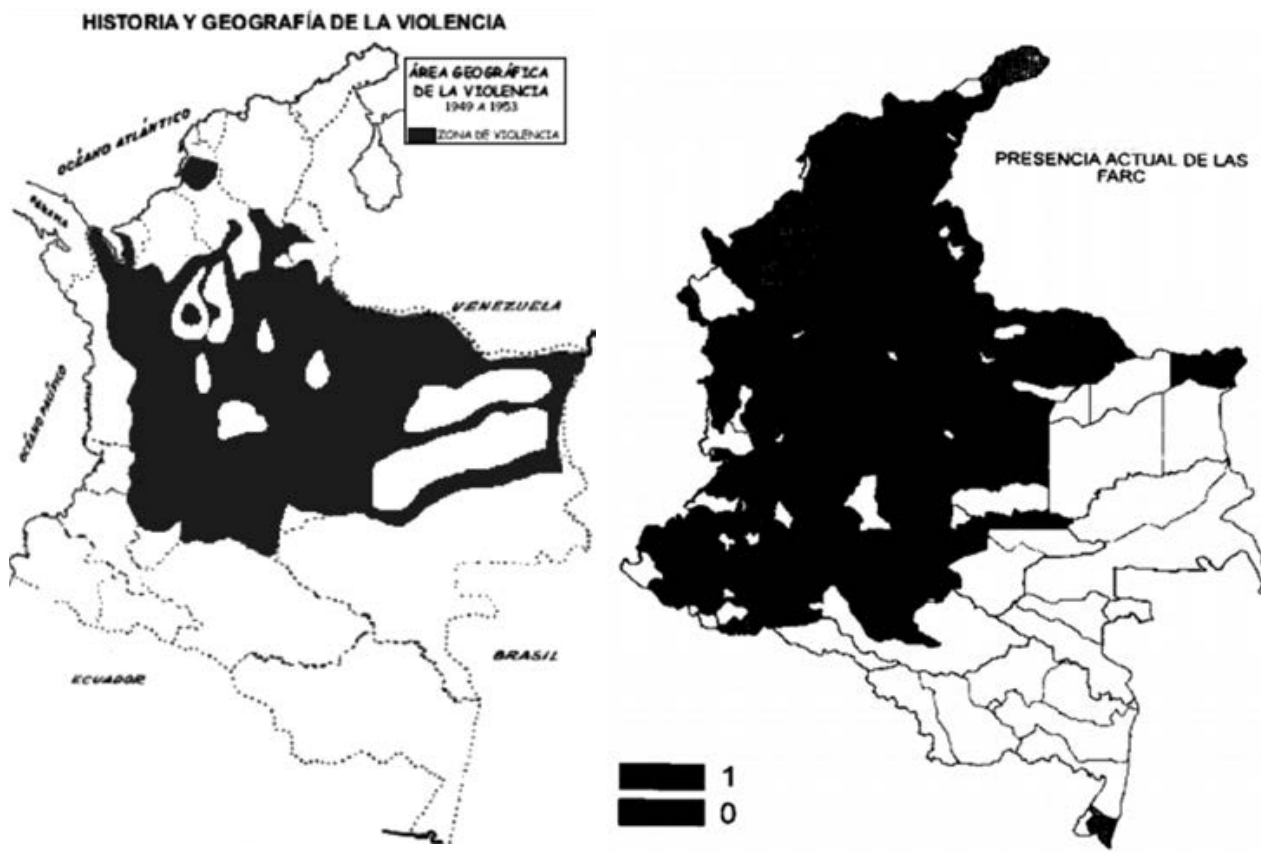

Fuente: Borda et al. (2010: 114); Vélez (2001: 221).

Otra representación espacial de la violencia derivada del conflicto armado y su proximidad al narcotráfico se encontraría en el trabajo del Observatorio Geopolítico de las Drogas (1996: 93), que muestra la relación entre las tierras adquiridas por el cártel de Medellín, los servicios de expansión hacia la costa Atlántica, el Pacífico, el centro del país y los Llanos Orientales, y la conexión entre enclaves productores, laboratorios de pasta y clorhidrato, y las pistas clandestinas, con salida al Mar Caribe. Una particular cartografía está presente en otros aportes como los de Vargas (1994), que regionaliza los diferentes cultivos de coca, marihuana o amapola; Echandía (1996; 2006), sobre rutas nacionales del tráfico de amapola y cocaína, o Betancourt (1991: 13), que recrea lo que denomina como los «cinco núcleos mafiosos de la droga» y que son el núcleo costeño, el antioqueño, el valluno, el central, el oriental y los «subcultivos sueltos».

Finalmente, hay otros trabajos destacables de alta calidad, como los de Reyes (2009), que investiga la relación entre despojo de tierra y paramilitarismo; Echandía (2006), que formula hipótesis sobre la relación entre la presencia de grupos y la concurrencia de fuentes de financiación, especialmente provenientes del cultivo ilícito, o Salas (2010; 2015), que arrojan luz sobre cómo se orienta la presencia, especialmente guerrillera, al control de rutas estratégicas de distribución, sobre todo de cocaína. Sin embargo, no predominan trabajos que traten de entender o abrir una línea explicativa 
MAPA 2.

RePresentaciones CARTOGRÁFICAS DE LOS CORREDORES DE LA DROGA EN COLOMBIA

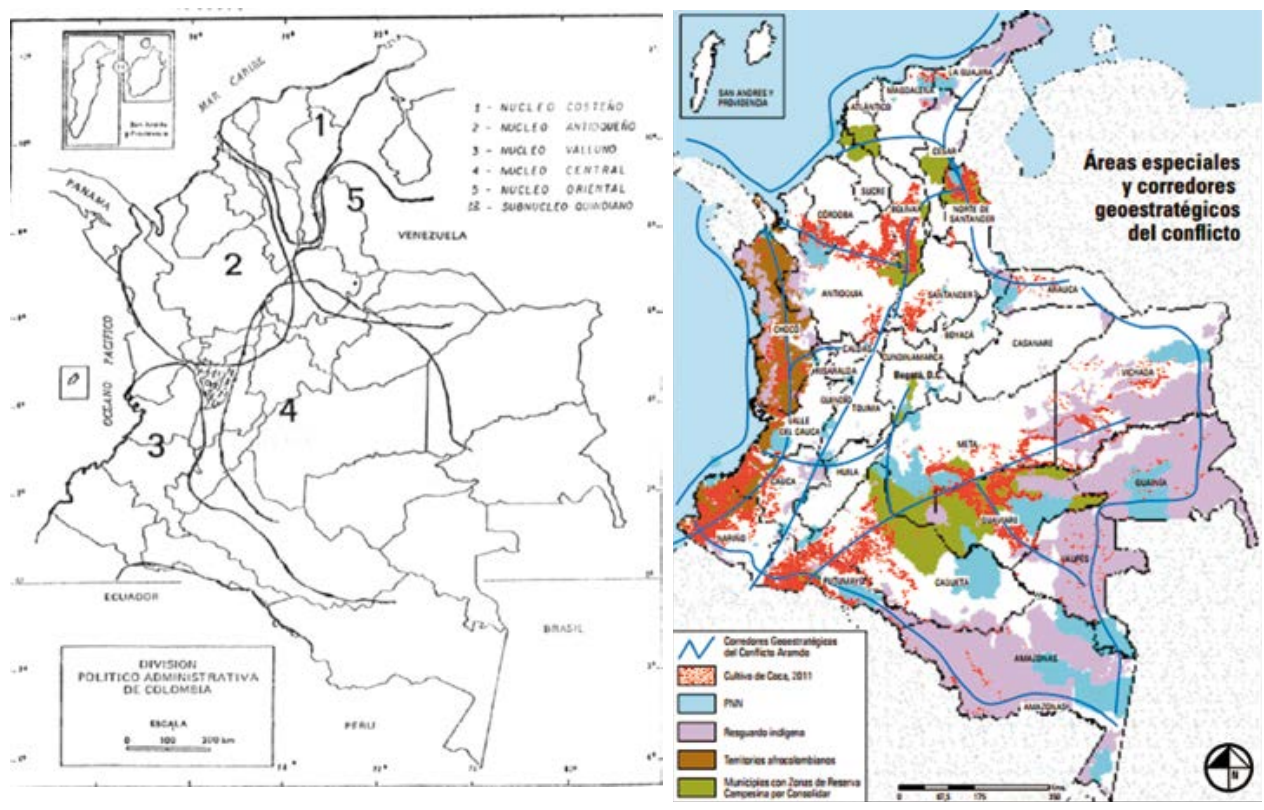

Fuente: Betancourt (1991: 30); Salas (2015: 168).

sobre la interacción entre los diferentes grupos armados involucrados en el conflicto armado colombiano a efectos de alcance, sentido o resultado.

Quizá, hasta el momento esto solo ha sido desarrollado parcialmente por el CINEP, que de manera prolífica, no obstante, ha realizado diversos estudios destacables, como el impacto en la Amazonía de las marchas cocaleras y su relación con los actores del conflicto armado (Ramírez, 2001); la relación entre cultivos y FARC en Caquetá (Ferro y Uribe, 2002), o la perspectiva regional en la comprensión de la violencia, lato sensu, en el sur del país (Vásquez, 2011; Torres, 2011; Rodríguez Cuadros, 2015), en el Oriente colombiano y la región de Urabá (García y Aramburo, 2011; González, 2012) o en la costa Caribe (González, 2014). Trabajos de alto valor agregado que, no obstante, pasan por alto la intrincada relación espacio-temporal mantenida, en estos escenarios, entre los grupos armados guerrilleros y las diferentes estructuras paramilitares.

\section{¿QUÉ SUCEDIÓ CUANDO LAS AUC Y LA GUERRILLA COINCIDIERON EN TIEMPO Y LUGAR?}

La anterior revisión de la literatura nos permite reivindicar la importancia que tiene la geografía política en la comprensión de un conflicto como el colombiano si 
bien, en lo que respecta a la interacción espacio-temporal de los grupos armados involucrados en el mismo, aún es mucho lo que queda por aportar. Sobre todo, por la tendencia a atribuir al paramilitarismo un factor de expulsión sobre las guerrillas que no resulta tan evidente, a tenor de lo que propone este trabajo, en las regiones del noreste y del suroeste del país.

Quizá, la afirmación anterior encontraría excepciones en los escenarios de mayor arraigo paramilitar en Colombia, tal y como sucede en el norte del país, donde el Bloque Norte (BN), según informa el CNMH, fue responsable entre 1998 y 2005 de más de ochenta masacres y casi seiscientas víctimas mortales, y se tiene firme conocimiento de que debilitó parte de la presencia guerrillera del ELN y de las FARC en la mayoría de los departamentos que conforman la región atlántica: Córdoba, Atlántico, Magdalena, Sucre, Bolívar, Cesar y La Guajira. De hecho, miles de combatientes del paramilitarismo menoscabaron los frentes 18, 19, 35, 37, 41 y 59 de las FARC, además del frente de guerra norte del ELN (Echandía, 2006; Medina, 2011).

Empero, igualmente conviene precisar que la costa atlántica, a su vez, respondía a unas particularidades específicas, en tanto que se trataba de un escenario con menor pie de fuerza y arraigo histórico por parte de las guerrillas, sin terreno selvático, montañoso y fronterizo que favoreciese sus lógicas de presencia y combate, y con una escasa presencia de cultivos ilícitos, fundamentales en las finanzas de los grupos

MAPA 3.

Presencia ARMAdA de Las AUC, 2002-2006
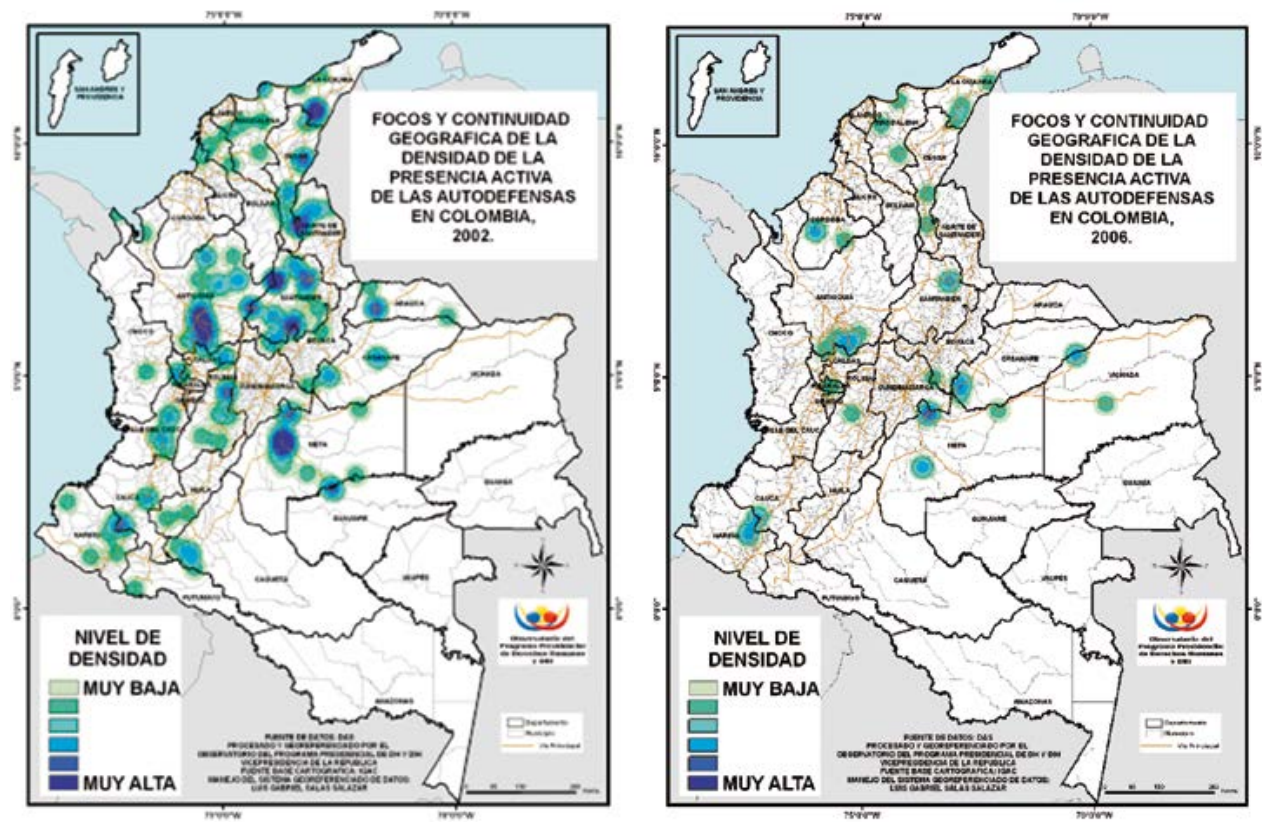

Fuente: ODHDIH (s.f.). 
MAPA 4.

PRESENCIA ARMADA DEL ELN, 1998-2006
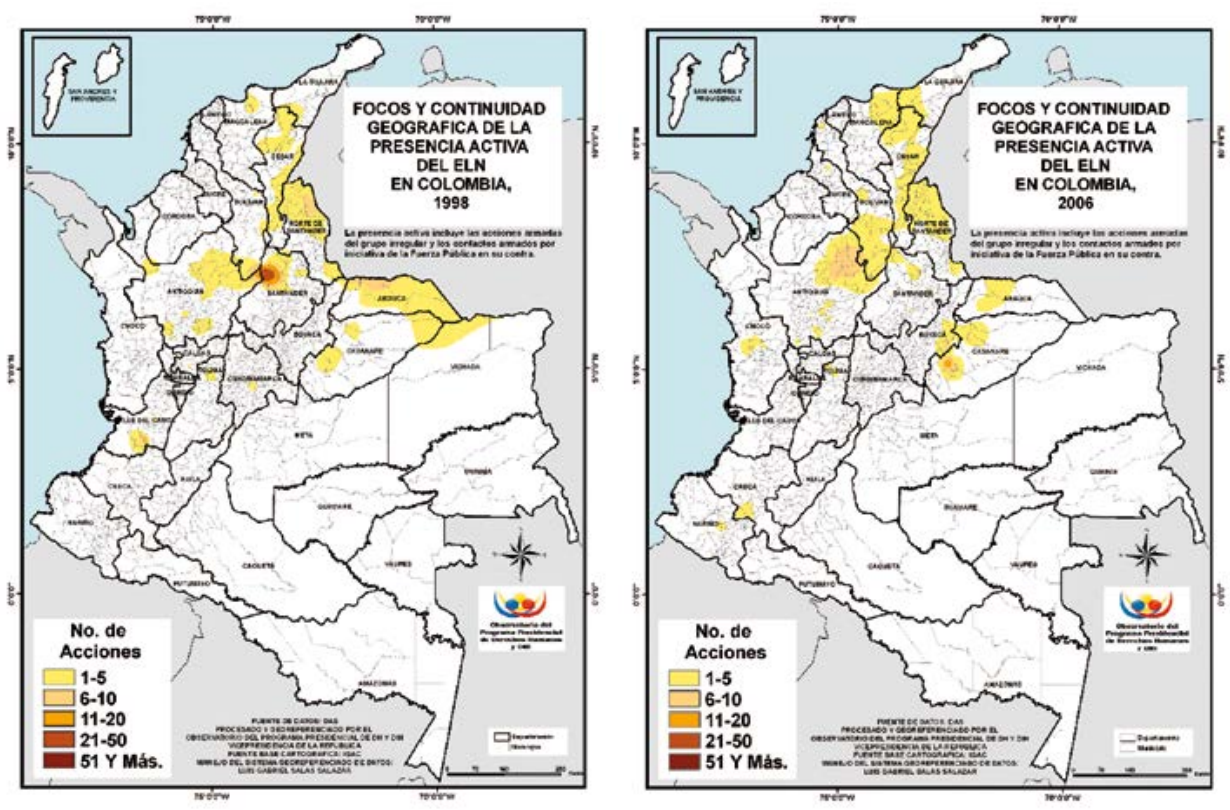

Fuente: ODHDIH (s.f.).

guerrilleros. Estos son cuatro elementos que, sensu contrario, son característicos del noreste y el suroeste, objeto de estudio de las siguientes páginas.

En relación con las dos regiones objeto de estudio de este trabajo, conviene señalar, antes de nada, que el noreste del país, en torno a los departamentos de Arauca y Norte de Santander, y la región suroeste, con los departamentos de Valle del Cauca, Cauca, Nariño, Huila, Tolima y Putumayo, son dos enclaves de gran arraigo guerrillero, tanto del lado de las FARC como del ELN. De un lado, la región nororiental tuvo un alto valor agregado estratégico y simbólico ${ }^{5}$, especialmente para el ELN por la presencia de sus frentes de guerra oriental y nororiental, conformados, entre otros, por la Compañía Simacota y el Frente Domingo Laín en el departamento de Arauca, además de la presencia de los frentes Carlos Armando Cacua Guerrero, Juan Fernando Porras y el frente urbano Carlos Germán Velazco, en Norte de Santander. De hecho, especialmente y hasta que entra el paramilitarismo en la región con el Bloque Vencedores de Arauca (BVA) y se inicia la guerra contra las FARC a inicios de la década pasada, el

5. Simbólicamente, esa región tiene un valor agregado muy importante para el ELN porque, desde 1965, se convirtió en uno de los enclaves nucleares desde los que se consideraba que se daban los factores estructurales y culturales necesarios para poner en marcha un proceso revolucionario, similar al acontecido en Cuba en 1959. 
ELN mantuvo una importante presencia en todos los municipios del departamento, con excepción de Fortul. Esto, gracias a la ingente fuente de ingresos que provenía tanto del contrabando de Venezuela como de la extorsión y las amenazas sobre el importante sector extractivo presente en el departamento.

Basta con observar cómo, únicamente entre 1998 y 2002, esta guerrilla llegó a acumular hasta 165 acciones guerrilleras por solo veintisiete operativos de la Fuerza Pública. Lo mismo sucedía con las FARC, muy activas por la presencia de los frentes 10 y 45, que compartieron (y disputaron) la presencia territorial al ELN, si bien con un nivel de violencia mucho mayor, que asciende entre 1998 y 2002 hasta las trescientas siete acciones, y que hacen de las FARC el actor hegemónico local en términos de activismo armado, superando con mucho los 85 operativos militares puestos en marcha contra las FARC por parte de la fuerza pública en estos años (ODHDIH, s.f.).

Junto con Arauca, en el noreste destaca el departamento de Norte de Santander y, muy particularmente, la región del Catatumbo, en disputa con los grupos paramilitares, por tratarse del centro nuclear cocalero por antonomasia, y con el valor agregado de ser un enclave fronterizo con Venezuela, pero conectado con corredores estratégicos hacia la costa atlántica ${ }^{6}$. En esta región del Catatumbo, conformada por los municipios de Abrego, Convención, El Carmen, El Tarra, Hacarí, La Playa, Ocaña, San Calixto, Sardinata, Teorama y Tibú, el ELN siempre fue muy activo y acumuló entre 1998 y 2005 un total de 159 acciones guerrilleras frente a 141 de las FARC. No obstante, con una tendencia bien distinta, desde 2002 el ELN empezó a perder el protagonismo local frente a unas FARC que encontraron en los cultivos del Catatumbo un bastión de gran valor para sus finanzas, lo que se tradujo en el aumento de cinco acciones guerrilleras en 1998 a 61 en el año 2005 (ODHDIH, s.f.).

La segunda región clave para las guerrillas colombianas se encuentra en el suroeste, favorecido por su distancia con los grandes centros económicos y políticos del país y por una geografía montañosa en el interior y selvática al sur; a esto se añade su condición fronteriza óptima con Ecuador y el océano Pacífico, en términos estratégicos, y una ingente presencia de cultivos cocaleros. La presencia del ELN en esta región siempre fue minoritaria, ausente en Huila y en Tolima, a excepción del norte, y poco relevante en el resto. Así, su activismo, en la costa del Pacífico se articuló en torno al Frente Comuneros del Sur en Nariño, el Frente Manuel Vásquez Castaño en Cauca y los frentes José María Becerra, Luis Carlos Cárdenas y el frente regional Omaira Montoya en Valle del Cauca -estos últimos, especialmente operativos en Cali, pero desmantelados desde el año 2000-. De hecho, en Nariño tendió a concentrarse en la zona occidental del departamento, en torno a la minería ilegal y el narcotráfico, si bien la región centro-oriental, que es donde prima la coca, siempre estuvo bajo la influencia de las FARC y sus frentes 2 y 29. Lo mismo ocurrió en Cauca, donde las FARC mantuvieron la hegemonía local en el que fue y siguió siendo hasta 2016 uno de sus tres

6. Tan importante es esta región que solo entre 1998 y 2005 llegó a albergar una superficie cultivada con coca superior a las 30000 ha (UNODC, 2015). 
MAPA 5.

Presencia ARMAda DE las FARC, 1998-2006
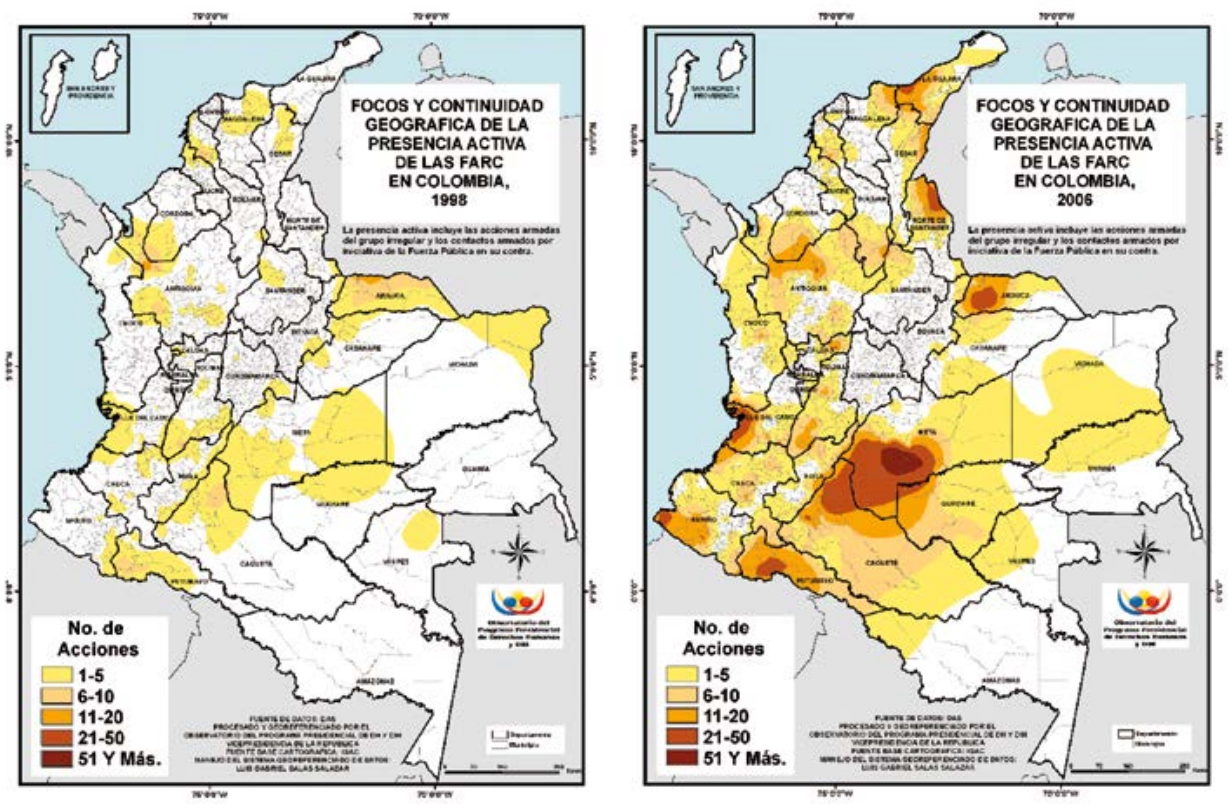

Fuente: ODHDIH (s.f.).

departamentos más importantes, al controlar la producción agrícola y cocalera con los frentes 8 y 60. En Valle del Cauca, como le sucediera al ELN, su presencia se desdibujaría, en mayor medida por el mayor arraigo paramilitar y el factor disuasorio de los cárteles de droga, que convergieron en debilitar la presencia de los Frentes 6 y 30.

Sea como fuere, las cifras respecto del arraigo de las guerrillas en este escenario hablan por sí solas. Entre 1998 y 2005 se produjeron 43 acciones del ELN en Nariño, 46 en Cauca y 44 en Valle del Cauca. Nada que ver con las 366 de las FARC en Nariño, las 231 en Valle del Cauca y 563 acciones en Cauca. Acciones a las que habría que añadir las causadas por el activismo del Bloque Sur a lo largo de la vertiente austral del corredor andino, que en Huila y Tolima supusieron otras 449 acciones adicionales (ODHDIH, s.f.). Por tanto, una notable presencia, especialmente de unas FARC atraídas por el valor estratégico de la región, pero también por la falta de capacidades de la fuerza pública ${ }^{7}$ y la notable presencia cocalera, donde se acumularon más de 100000 ha cultivadas con coca entre 1998 y 2005 (UNODC, 2015).

7. Entre 1998 y 2005, el ELN fue objeto de 73 acciones de la fuerza pública en Cauca, 48 en Nariño y cincuenta en Valle del Cauca. A su vez, las FARC sufrieron 374 acciones en Cauca, 253 en Nariño y 220 en Valle del Cauca, es decir, significativamente por debajo del activismo armado de las guerrillas (ODHDIH, s.f.). 
Llegados a este punto, es momento de presentar lo que sucedió cuando coincidieron en el tiempo las AUC con las guerrillas de las FARC y el ELN en aquellos departamentos descritos, y conforme a los indicadores explicitados al inicio del artículo. Unas AUC cuyos grupos objeto de estudio son el Bloque Sur, el Bloque Calima, el Bloque Pacífico, el Bloque Libertadores del Sur, el Bloque Catatumbo y el Bloque Vencedores de Arauca. Estos, por ser aquellos que fuera del norte del país resultaron ser los más activos en la confrontación que transcurre entre 1998 y 2005 contras las guerrillas de las FARC y el ELN en Colombia.

\section{Bloque Sur (BS)}

El Bloque Sur (BS) surgió a finales de 1996, y fue creado, como el resto de casos objeto del análisis, por la conocida Casa Castaño ${ }^{8}$. Su intención pasaba por apropiarse de la ruta del narcotráfico de Putumayo, departamento que se había erigido como el mayor productor de coca de todo el país, con más de 40000 ha cultivadas. Sin embargo, la verdadera presencia del grupo en el departamento se corresponde con las masacres de El Tigre y El Placer en 1999, y siendo especialmente violento entre los años 2000 y 2002. Fue uno de los grupos más tardíos en desmovilizarse, el 1 de marzo de 2006, si bien desde 2005 no se tuvo constancia de activismo alguno.

\section{GrÁFICO 1.}

Activismo de las FARC Durante el CONTROl Paramilitar del BS, 1998-2006

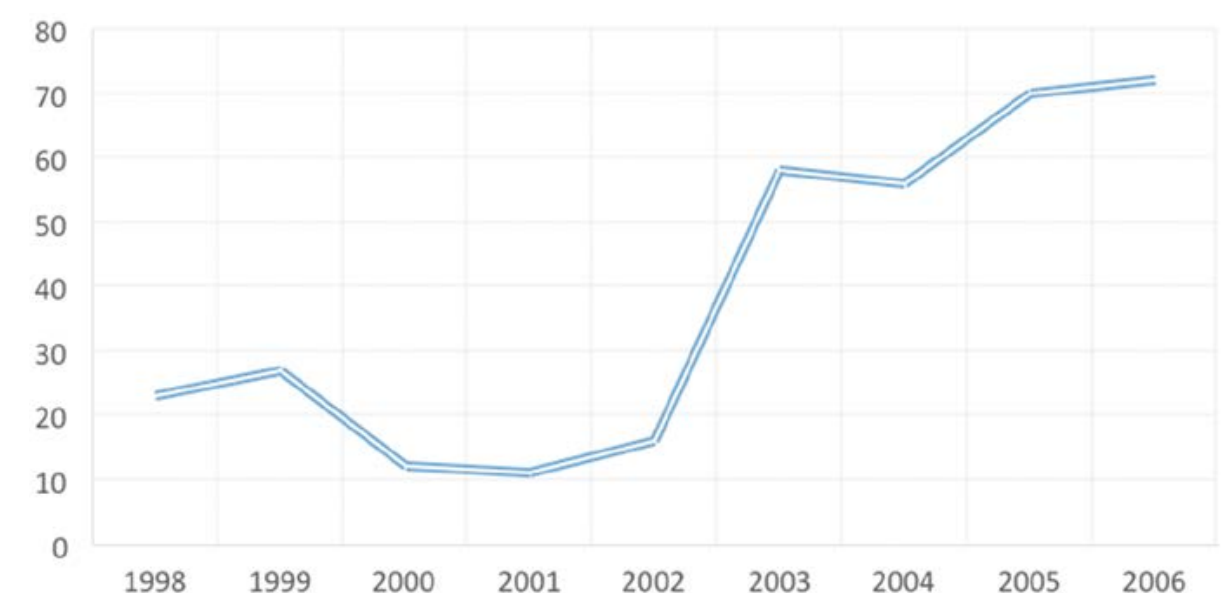

Fuente: elaboración propia a partir de datos del ODHDIH (s.f.).

8. Por «Casa Castaño» se entiende a la familia de los tres hermanos Castaño: Fidel, Carlos y Vicente, que son los creadores de toda la estructura paramilitar colombiana desde la década de los noventa y, muy especialmente, una vez desarticulados los cárteles de Medellín y Cali. 
Los principales ámbitos de acción del BS fueron el medio y bajo Putumayo, y concretamente los municipios de Puerto Asís, Valle del Guamuez, San Miguel, Orito, Puerto Guzmán, Puerto Caicedo y Villagarzón. Siete municipios que en seis años fueron testigos de hasta dieciocho masacres con un bagaje de 236 víctimas mortales, lo que hace del BS uno de los más violentos en promedio, con más de trece víctimas mortales por masacre. Sin embargo, entre 1998 y 2006 y, precisamente, lejos de remitir la presión guerrillera, lo que se evidencia es un incremento cualitativo y cuantitativo de los Frentes 32, 48 y 63 de las FARC, presentes en el departamento, toda vez que no se aprecia presencia alguna de la guerrilla del ELN.

Si entre 1998 y 2002 se dieron en Putumayo entre veinticinco y treinta acciones guerrilleras protagonizadas por las FARC, allí donde se encontraba el BS, en el período posterior entre 2003 a 2006, estas se elevaron a 75 acciones por año. Un preocupante registro que, pese a decaer en 2007 y 2008, se recompuso, en términos estables y de manera sostenida, hasta antes del abandono de las armas y el acuerdo de paz en 2016, lo cual redunda en la lógica de continuidad y hegemonía armada que las FARC tuvieron en Putumayo. En otros términos, la magnitud del activismo guerrillero en estos municipios fue tal que, lejos de remitir, aumentaron. Las acciones armadas de las FARC ascendieron entre 1998 y 2006 a 67 en Puerto Asís, 62 en Valle del Guamuez, 74 en San Miguel, 92 en Orito, veinte en Villagarzón, veintisiete en Puerto Caicedo y diez en Puerto Guzmán, experimentando así unos niveles de presencia y activismo armado nunca vistos hasta entonces en el departamento, lo que echa por tierra cualquier atisbo de posible expulsión a cargo del BS.

\section{El Bloque Calima (BCA)}

El Bloque Calima (BCA) surgió en 1999 por demanda de muchos empresarios de la región de los departamentos de Valle y Cauca que buscaban protección frente a la guerrilla, y por demandas explícitas del cártel del Norte del Valle ${ }^{9}$, que encontró en el paramilitarismo una perfecta fuente de protección (CNMH, 2012; López, 2008). Su ámbito de acción hasta diciembre de 2004, cuando se produjo su desmovilización, se extendió a prácticamente todo el departamento de Valle, buena parte del norte de Cauca y focos concretos del sur de Huila y Quindío. Como resultado, en apenas cuatro años dejó un total de 45 masacres y 323 muertes.

En el departamento de Cauca, el BCA entre 2000 y 2004 concentró su presencia en el norte, en los municipios de Buenos Aires, Santander de Quilichao, Suárez y Corinto; en la región central, en torno a la capital, Popayán, El Tambo, Patía y Timbío; y al sur, en Piamonte. En todos estos municipios, durante los años de expansión paramilitar se registró una presencia notable de las FARC a través de su Frente 8,

9. El cártel del Norte del Valle sobrevivió a la desaparición de Medellín y Cali para controlar el negocio del tráfico de drogas y las rutas hacia México, Venezuela, Europa y Estados Unidos. 
especialmente en El Tambo ${ }^{10}$ (23), Corinto (21), Santander de Quilichao (19) y Patía (14); en menor medida en Popayán (8) y Timbío (7), y mucho menos relevante en Suárez (5) y Piamonte (3) (ODHDIH, s.f.). En todo caso, eran enclaves caracterizados por una notable presencia de cultivos ilícitos: estos municipios llegaron a acumular hasta 12000 ha cultivadas entre 2000 y 2004 (UNODC, 2015).

Como en el caso anterior, cabría cuestionar el factor de expulsión del paramilitarismo sobre las FARC, especialmente en un departamento como este, prioritario para sus intereses. Si entre 1998 y 2001 las acciones de esta guerrilla giraron en torno a una treintena de acciones armadas por año, estas terminaron por triplicarse en los años siguientes, llegando, incluso, a las 150 acciones armadas anuales, como sucedió entre 2003 y 2005. Tras decaer a setenta acciones guerrilleras, desde 2010 se ha asistido nuevamente a un proceso irrefrenable de presencia y activismo guerrillero, próximo a las doscientas acciones armadas anuales y que solo decayó una vez suscrito el cese al fuego bilateral, ya en 2015. Es más, en ninguno de los municipios en los que tuvo presencia el BCA en Cauca hasta 2004 no se apreció reducción alguna del activismo de las FARC (ODHDIH, s.f.).

En lo que respecta al ELN, el norte de Cauca nunca fue su prioridad, de manera que la lógica de presencia paramilitar del BCA en esta parte del departamento apunta, claramente, a municipios con presencia de FARC. En cuanto a la región central, es donde más se evidencia su activismo guerrillero, especialmente, entre 1998 y 2001, cuando se acumulan ocho acciones guerrilleras en Popayán (2), Timbío, (3) Patía (2) y El Tambo (1), provenientes del Frente Manuel Vásquez Castaño, operativo en esta región, y que termina replegado desde 2002 por la suma de enemigos: paramilitarismo, las FARC y la fuerza pública. De hecho, entre 2004 y 2010 no se tiene constancia del ELN en el departamento hasta que el recrudecimiento del conflicto en el Pacífico entre 2010 y 2012 le lleva a protagonizar nuevamente hasta diecisiete acciones armadas, la mayoría en la región central, en torno a Popayán y municipios aledaños (ODHDIH, s.f.).

En cuanto al Valle del Cauca, el paramilitarismo se extendió con fuerza a lo largo de todo el departamento, siendo especialmente incisivo en los municipios de Buga, Bugalagrande, San Pedro, Tuluá, Sevilla, Buenos Aires, Calima del Darién, y Jamundí. Entre 1998 y 2002 se observa un bajo nivel de activismo guerrillero en el Valle del Cauca. De hecho, el cártel del Norte del Valle, unido al paramilitarismo, se consolidó como el actor violento de mayor importancia. Durante dicho periodo se registraron solo quince acciones anuales de las FARC, apreciándose solo un activismo importante en Tuluá, donde se acumularon nueve acciones del Frente 30 y seis del Frente 6, mientras era residual la presencia en Buga (3), Sevilla (3) y Jamundí (4), e inexistente en el resto de municipios (ODHDIH, s.f.).

En otras palabras, durante la emergencia del BCA, salvo Tuluá, los enclaves de disputa de control territorial sobre la guerrilla fueron poco coincidentes, y allí donde coincidieron son poco significativos. Sorprendentemente, desde 2003 y hasta 2007, el

10. Entre paréntesis, el número de acciones guerrilleras. 
departamento experimentó un crecimiento sin precedentes del activismo guerrillero, invitando a pensar en el aprovechamiento del espacio de poder dejado por el BCA una vez que se desmoviliza. De hecho, las acciones insurgentes de las FARC se triplicaron, ascendiendo casi al centenar en el año 2006 y manteniéndose estables hasta 2013. Esto cuestiona nuevamente la desaparición de las FARC del departamento como consecuencia del paramilitarismo. En cuanto al ELN, el factor de expulsión paramilitar sí que podría vislumbrarse de mayor manera, pues desde el año 2000 la guerrilla desapareció del departamento, en buena medida por ser en Cali, su centro de operaciones, donde el incremento de la política de seguridad, así como los medios de la violencia derivada del narcotráfico y el paramilitarismo confluyeron en su desmantelamiento.

Finalmente, en el departamento de Huila la presencia paramilitar fue importante en el municipio limítrofe departamental de Pitalito, masacrado en 2002 y que siempre tuvo presencia de las FARC. Una presencia que incluso llegó a las diez acciones guerrilleras en ese mismo año 2002, y que mantuvo niveles importantes en los siguientes, especialmente entre 2003 y 2004, fruto de la acción de columna móvil Teófilo Forero, una columna replegada entre 2005 y 2010 , pero reactivada desde entonces y hasta entrado el proceso de negociación en el departamento. Otros municipios con impacto de este BCA en Huila fueron Gigante, Elías, Guadalupe, Acevedo, San Agustín e Isnos, todos igualmente de escaso arraigo guerrillero y poco importantes en la geografía de la violencia de las FARC a nivel departamental, lo cual muestra que la presencia guerrillera, en este caso, fue tan continua como poco afectada por el factor paramilitar al ocupar, guerrilla y paramilitarismo, escenarios territoriales claramente distanciados.

\section{GRÁFICO 2.}

ACtivisMo GUERRILLERO DURANTE EL CONTROL PARAMILITAR DEL BCA, 1998-2006

ELN Cauca $\overline{=}$ ELN Valle $=$ FARC Valle $=$ FARC Cauca $\bar{\equiv}$ FARC Huila

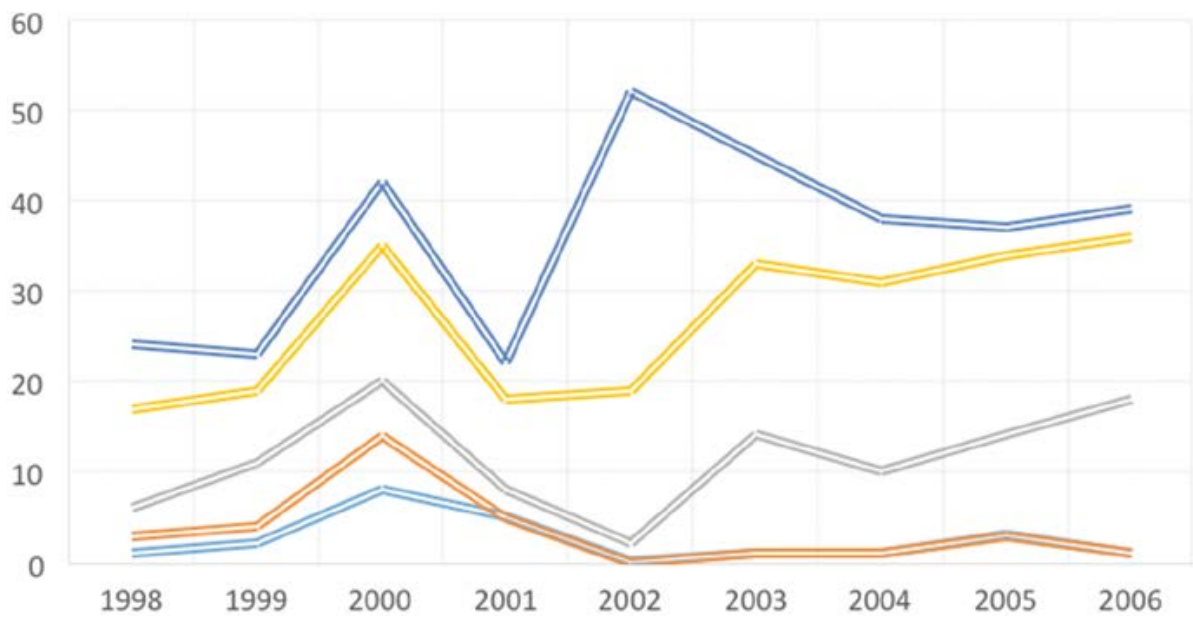

Fuente: elaboración propia a partir de datos del ODHDIH (s.f.). 


\section{El Bloque Pacifico (BP)}

El Bloque Pacífico (BP), inicialmente surge dentro del BCA, aunque a partir del año 2000 los Castaño deciden venderlo al conocido narcotraficante Gordolindo, quien adquiere la facción paramilitar para crear un bloque autónomo que actuará por cuenta propia hasta su desmovilización, el 23 de agosto de 2005, dentro de un proceso que en los meses anteriores hizo que el grupo desistiese de masacres y acciones armadas. Así, este BP se concentró en torno a la ciudad de Buenaventura, la segunda ciudad del departamento tras Cali, y el puerto más importante del Pacífico colombiano. En ella se dieron hasta 2014 un total de quince masacres y 121 muertes violentas, especialmente entre 2001 y 2003 (CNMH, s.f.).

Durante todo este tiempo, Buenaventura es hostigada, igualmente, por las FARC, y su Frente $30^{11}$, si bien las acciones de la guerrilla entre 1998 y 2002 apenas ascienden a cuatro de promedio al año. No obstante, desde 2003 y hasta 2005, mientras se mantiene activo el BP, estas acciones se sextuplican y llegan hasta casi la veintena. Una dinámica creciente e irreversible que crece exponencialmente tras la desmovilización de 2005, cuando se contabilizan, solo en 2006, hasta 46 acciones guerrilleras. Este volumen nuevamente cuestiona el factor de expulsión paramilitar sobre la presencia de unas FARC hasta 2015 fuertemente arraigas en la ciudad y el departamento (ODHDIH, s.f.).

\section{GRÁFICO 3.}

ACTIVISMO GUERRILLERO DURANTE EL CONTROL PARAMILITAR DEL BP, 1998-2006
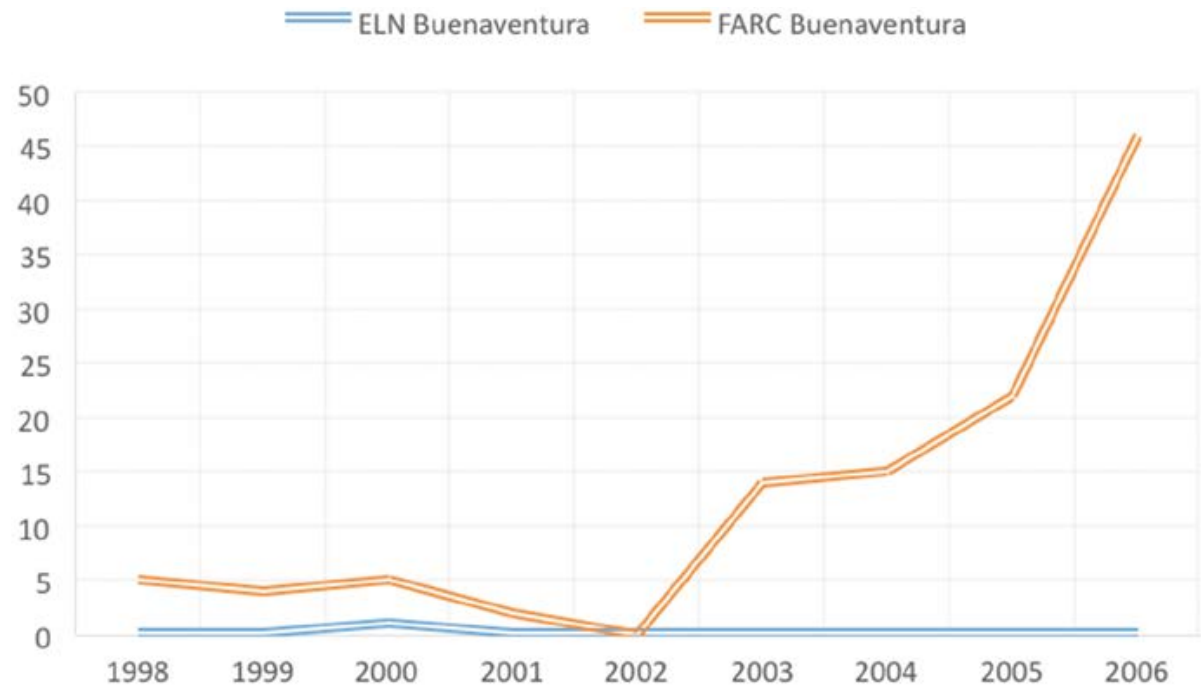

Fuente: elaboración propia a partir de datos del ODHDIH (s.f.).

11. No se registra en este tiempo presencia alguna del ELN. 
Bloque Libertadores del Sur (BLS)

El Bloque Libertadores del Sur (BLS), también creado por los Castaño en 1999, respondió al mismo plan de expansión de las AUC por el país, sobre todo una vez consolidada su posición en el norte de Colombia. Este BLS se organizó en torno a tres frentes, íntegramente activos en el departamento de Nariño: Héroes de Tumaco y Llorente, Lorenzo Aldana y las Brigadas Campesinas Antonio Nariño. Ello, de acuerdo a una financiación proveniente netamente de la extorsión y del narcotráfico.

Solo en Tumaco, Barbacoas, Samaniego, Ipiales, Túquerres y La Unión, el BLS protagonizó hasta dieciséis masacres entre 1999 y 2004, con el resultado de 125 muertes violentas (CNMH, s.f.), siendo especialmente intenso el período entre 2001 y 2003. Además, hubo un importante arraigo paramilitar en otras localidades como Francisco Pizarro, Mosquera, Roberto Payán, Llorente, Pasto, Taminango, Ricaurte y Policarpa, Magüí Payán, Olaya Herrera, Santa Bárbara y La Tola.

De los dieciocho municipios con mayor presencia e influencia paramilitar durante los años de activismo del BLS, en siete de ellos la preponderancia del Frente 29 de las FARC resultó muy significativa. Tanto, que entre 1999 y 2005 se registran quince acciones guerrilleras en Samaniego, catorce en Ipiales, cuarenta en Tumaco, veintidós en Barbacoas, 35 en Pasto, 42 en Ricaurte y diez en Policarpa ${ }^{12}$ (ODHDIH, s.f.).

Igualmente, se evidenció una presencia, aunque muy minoritaria, del ELN, que en estos años experimentó, además, un fuerte declive en su activismo guerrillero por las constantes tensiones con las FARC, que le llevaron a un conflicto con la guerrilla muy similar al acontecido en Arauca. No obstante, entre 2000 y 2003, que son los años de su mayor intensidad, y prácticamente hasta su reaparición en $2010^{13}$, apenas contabilizan 34 actividades guerrilleras, la mitad de las mismas focalizadas en los referidos municipios de Túquerres (2), Taminango (1), Samaniego (8), Barbacoas (1), Tumaco (1), Pasto (2), Ricaurte (1) y Policarpa (1).

Como sucediera en Putumayo, Nariño responde a una prioridad regional en el que el arraigo territorial, las ventajas competitivas por su condición geográfica y fronteriza, la industria del narcotráfico y la presencia de las FARC juegan un papel muy importante. De hecho, los niveles de violencia de las FARC se vieron inalterados en la mayoría de los municipios referidos, afectados por la presencia paramilitar, y tanto durante la persistencia del fenómeno como después, tras su desmovilización. Es más, el activismo, como muestra el siguiente gráfico, se intensificó sustancialmente en municipios como Ipiales, Ricaurte, Roberto Payán, Tumaco o Barbacoas, reduciéndose únicamente para el caso de la capital, Pasto, y haciendo del departamento y junto con Cauca y hasta el año 2016, el enclave prioritario y nuclear de la presencia de las FARC en Colombia.

12. No obstante, se registra presencia minoritaria en Magüí Payán (1), Olaya Herrera (2), La Tola (5), Taminango (2) y Túquerres (1) (ODHDIH, s.f.).

13. Desde 2010 y hasta 2012 el ELN, por ejemplo, protagoniza en Nariño hasta 36 acciones guerrilleras (ODHDIH, s.f.). 
GrÁFICO 4.

ACTIVISMO GUERrillero DURANTE EL CONTROL PARAMILITAR DEL BLS, 1998-2006

ELN Nariño $=$ FARC Nariño

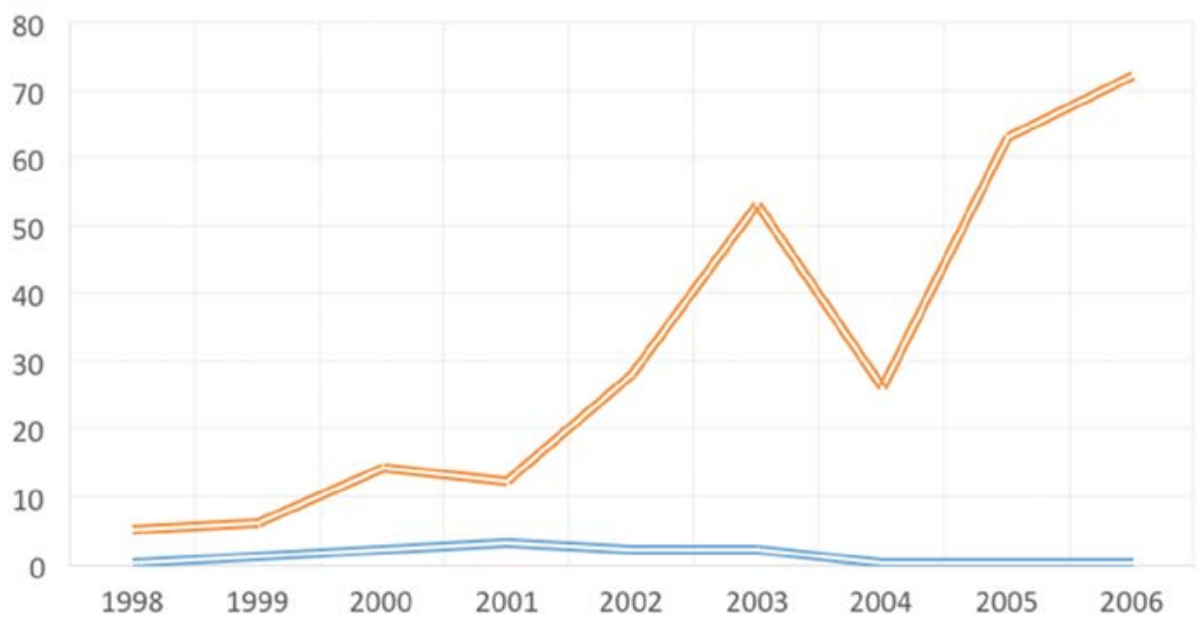

Fuente: elaboración propia a partir de datos del ODHDIH (s.f.).

\section{Bloque Catatumbo (BCAT)}

El Bloque Catatumbo (BCAT) se conformó en 1999 por el interés de ingresar en la región a través del sur de César, a efectos de forzar por parte de los hermanos Castaño una eventual negociación del ELN con el Gobierno de Andrés Pastrana -en ese momento en negociación con las FARC en el conocido como "proceso del Caguán»-. Empero, esta región, en realidad, suponía un enclave prioritario por la conexión con uno de los mayores escenarios de producción de coca del país como es el Catatumbo.

El propio jefe paramilitar, Rodrigo Doble Cero, reconoció en su momento que la intención de los Castaño era apoderarse de los medios financieros de la guerrilla (CNMH, 2013), para lo cual llegaron a operar en medio centenar de municipios, esto es, casi la totalidad del departamento, con la excepción de El Carmen y Teorama. No obstante, los municipios más afectados por esta presencia paramilitar fueron la capital departamental, Cúcuta, y los municipios de El Zulia, El Tarra, Tibú, Salazar, Sardinata y Villa del Rosario, donde, entre 1999 y 2003, se acumularon hasta veintitrés masacres y 188 muertes violentas.

En lo que respecta a las FARC, entre 1998 y 2001 su activismo armado era reducido, por debajo de las ocho acciones anuales, y siempre de manera dispersa, a excepción de Tibú, la localidad por antonomasia productora de coca en la región. Sin embargo, desde 2001 su presencia crece sustancialmente, y en 2002 se contabilizan veinte acciones armadas, atribuidas al Frente 33, de las cuales, tres cuartas partes se 
GRÁFICO 5.

ACTIVISMO GUERRILLERO DURANTE EL CONTROL PARAMILITAR DEL BCAT, 1998-2006
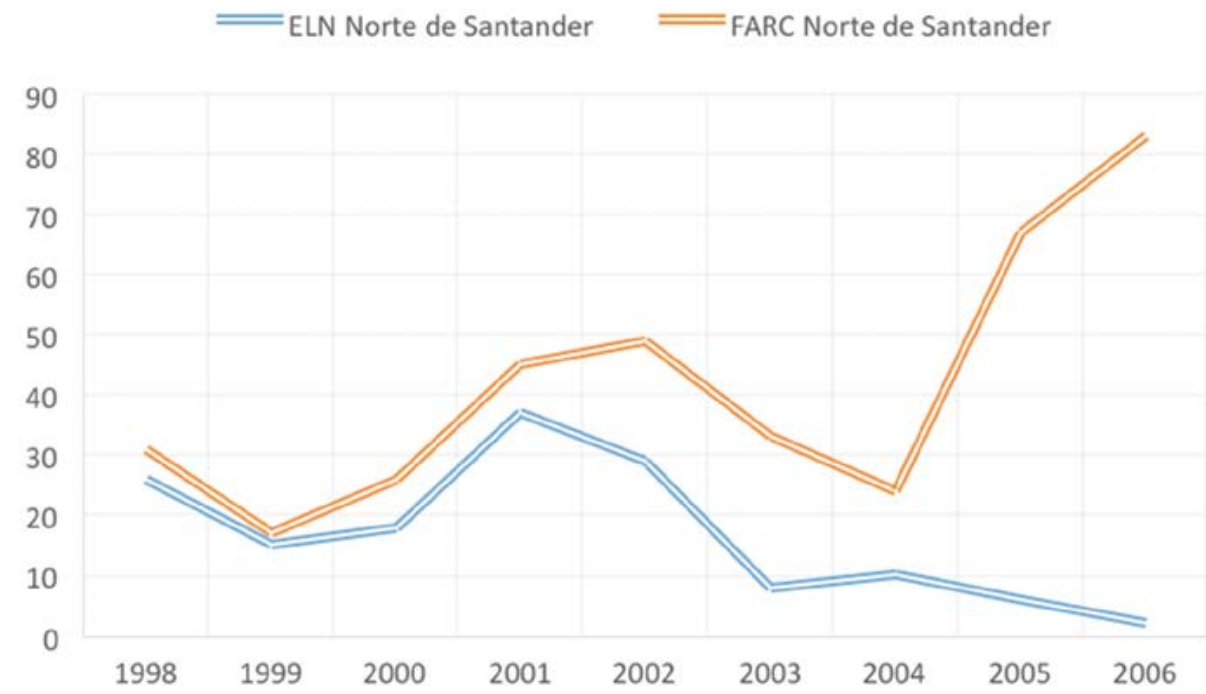

Fuente: elaboración propia a partir de datos del ODHDIH (s.f.).

condensan sobre escenarios en disputa con el paramilitarismo como Tibú o Cúcuta. Lejos de remitir, en 2003 las acciones ascienden a veinticinco, de las cuales dieciocho repiten, nuevamente, en municipios de disputa con el paramilitarismo. Y aunque en 2004, una vez desmovilizado el BCAT, las acciones de las FARC decaen a catorce, un año después, en 2005, muestran un registro, calificado hasta ese momento de "histórico», de 61 acciones armadas que, no solo impiden entender la afectación paramilitar sobre las FARC en su región, sino que se mantendrá casi inalterada hasta bien entrado el proceso de paz con la guerrilla (ODHDIH, s.f.).

Con el ELN sucedió algo diferente, pues entre 1998 y 2002 actuó como el grupo armado más importante, acumulando hasta 133 acciones guerrilleras en buena parte de la totalidad del departamento, pero, especialmente, en contextos de coincidencia con las FARC y con el BCAT, tal y como fueron los casos de El Tarra, El Zulia, Cúcuta, Tibú y Sardinanta. Sin embargo, si hacia 2003 las FARC evidenciaban un proceso de fortalecimiento y protagonismo creciente, al contrario en el ELN las acciones decaen a mínimos históricos, con apenas una decena de acciones armadas, y en 2004 se llegó casi a la completa inacción. Esto fue consecuencia de un proceso de paulatino repliegue, a tenor del fuego cruzado con las FARC y el paramilitarismo, de manera que hubo que esperar casi hasta 2009 para su recomposición en el departamento y su nuevo marco de alianza con las FARC, vigente hasta $2015^{14}$.

14. En 2005 y 2006, las acciones del ELN caen a mínimos históricos. Por ejemplo, se recogen solo dos acciones del ELN en todo el departamento de Norte de Santander -El Tarra (1) y Sardinata 


\section{Bloque Vencedores de Arauca (BVA)}

Finalmente, el último de los grupos, el BVA, tuvo como origen la voluntad de Carlos Castaño, hacia mediados del año 2000, de disputar el control territorial que sobre Arauca se repartían el Bloque Oriental de las FARC y buena parte del ELN. La tarea de comandar la creación del paramilitarismo recayó, en esta ocasión, en los hermanos Mejía, conocidos como los Mellizos, y que según versiones libres al amparo de Justicia y Paz, compraron la estructura paramilitar por cinco millones de dólares ${ }^{15}$.

El bloque surgió con doscientos combatientes, de los cuales la mitad fueron reclutados en el municipio de Barranca de Upía, y la otra parte provino de parte del Bloque Centauros ${ }^{16}$. Así, el grupo se mantuvo hasta diciembre de 2005, focalizando sus acciones de extorsión, despojo de tierras y narcotráfico en torno a los municipios urbanos de Saravena, Tame, Arauca, Arauquita, Cravo Norte y Puerto Rondón, sobre todo entre 2002 y 2004, (CNMH, 2013), dejando tras de sí un bagaje de once masacres y 84 víctimas mortales (CNMH, s.f.), pero que, como en la mayoría de los casos expuestos, no se corresponden con factor de expulsión alguno sobre las guerrillas. En el caso de las FARC porque entre 2000 y 2006 sus acciones mantuvieron niveles estables y bajo pautas similares a las otras mencionadas. Es decir, en los años de mayor activismo paramilitar se condensó el mayor número de acciones guerrilleras, tal y como puede verse en el siguiente gráfico, especialmente por el activismo de los Frentes 28, 10 y 45 en el departamento. Tanto, que Arauca terminó siendo un enclave prioritario para las FARC, incluso una vez desaparecido el BVA, pues solo en 2006 se contabilizarían hasta 55 acciones guerrilleras -Tame (22), Arauquita (13), Arauca (9), Fortul (7), Puerto Rondón (2) y Saravena (2)-, superando el promedio acumulado desde el año 2000 por esta guerrilla en el departamento (ODHDIH, s.f.).

Por su parte, el ELN hacia 2005 prácticamente se había replegado en el departamento, en un proceso similar al de Norte de Santander, fruto de la confrontación directa que hasta ese entonces habían mantenido con las FARC. Así, basta con observar cómo aquel año el ELN apenas protagonizó cuatro acciones armadas -Arauca (2), Arauquita (1), Saravena (1)-, lo cual supone una cifra muy alejada de las 54 acciones del año 2001 o incluso de las 27 acciones de 2003. No obstante, nunca desparecerá por completo del departamento y una vez sellada la pax guerrillera con las FARC en 2009, se recompondrá paulatinamente, hasta convertir nuevamente Arauca como su centro nuclear de activismo y presencia territorial, tal y como sucede hoy en día con motivo del más que notable protagonismo que el Frente de Guerra Oriental mantiene en el departamento.

(1)-, si bien el activismo se reactiva desde 2009, como muestran las veintidós acciones guerrilleras llevadas a cabo en ese año (ODHDIH, s.f.).

15. Véase: http://www.eltiempo.com/archivo/documento/CMS-3861926 (consultado el 27 de agosto de 2015).

16. El Bloque Centauros fue un bloque paramilitar activo desde 1997 en los Llanos Orientales, específicamente en los departamentos de Meta, Guaviare y Casanare. 
GrÁFICO 6.

ACtivismo guerrillero durante El CONTROL PARAMilitar DEL BVA, 1998-2006

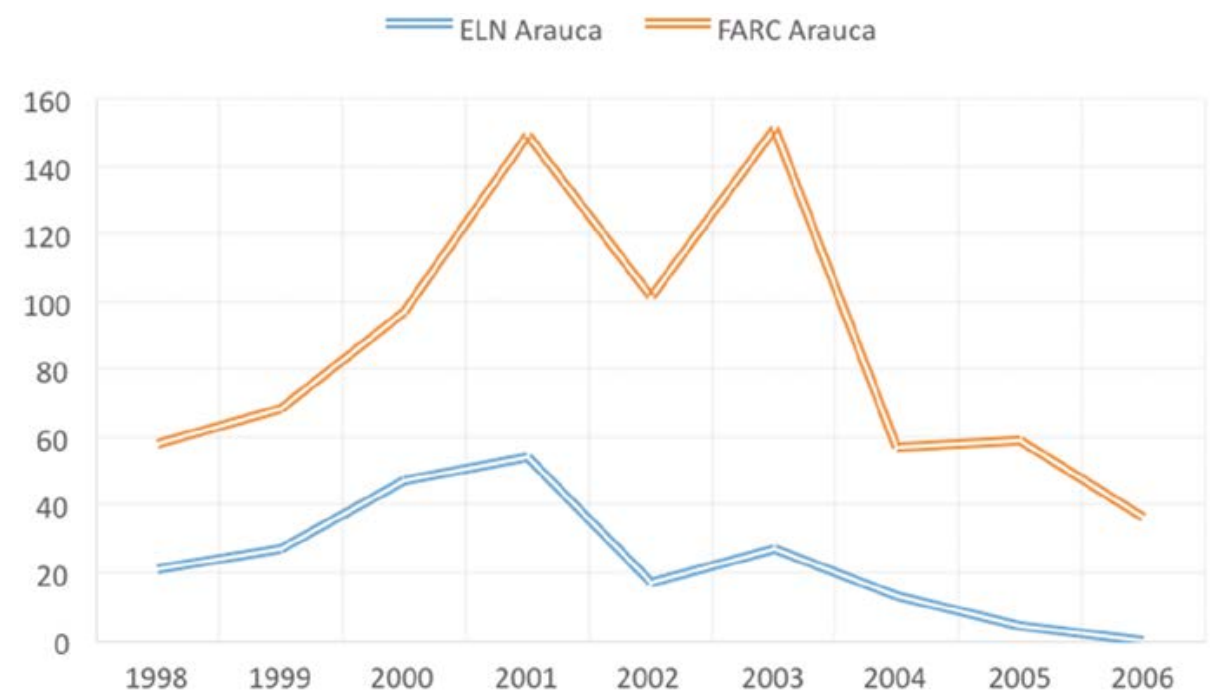

Fuente: elaboración propia a partir de datos del ODHDIH (s.f.).

\section{CONCLUSIONES}

A la vista de los resultados expuestos, una primera conclusión es la importancia del arraigo local de las guerrillas en las dos regiones objeto de análisis, especialmente en el caso de las FARC, las cuales mantuvieron estables, cuando no crecientes, la mayoría de sus dinámicas de activismo armado allí donde coincidieron en tiempo y lugar con el paramilitarismo. Es decir, no se observa ninguna influencia significativa de parte de las AUC en las regiones objeto de estudio: el noreste y el suroeste colombiano. Ninguno de estos escenarios fue oriundo del proyecto paramilitar; al contrario, fueron objeto de disputa a partir de 1998, en el que las AUC buscaron arrebatar el control de los espacios cocaleros allí donde las FARC se habían consolidado desde décadas atrás.

Incluso cuando los grupos paramilitares se desmovilizan al amparo de la Ley 975 de 2005, conocida como ley de justicia y paz, se dio una presumible situación de consolidación local de la guerrilla de las FARC en uno y otro lugar. Ello porque la desaparición del paramilitarismo supuso la desactivación del único actor armado que, hasta ese momento, había conseguido confrontar directamente contra las guerrillas -con éxito en el norte del país - y habida cuenta de que la fuerza pública se hallaba focalizada en otras prioridades regionales como Cundinamarca, Antioquia, Santander, Meta o el eje cafetero, donde no había el grado de condición selvática, fronteriza y cocalera, donde tuvo mayor presencia el paramilitarismo y, por extensión, la guerrilla 
A lo anterior contribuyó igualmente el hecho de que la desmovilización de más de 31000 efectivos de las AUC en 2005 no se acompañase de una reforma estructural, social, económica y política, lo cual permitió la transformación del paramilitarismo colombiano. Un paramilitarismo que se redefinió en forma de nuevas bandas emergentes de cariz criminal a partir de 2008, y que empezó a operar, ya desideologizado, en los mismos enclaves cocaleros del noreste y del suroeste colombiano, aunque bajo una impronta de mayor colaboración y menor confrontación con las guerrillas; una situación inédita por su naturaleza, pero que responde al profundo arraigo territorial y armado de las FARC y al rearme del ELN, especialmente en el noreste, y que debe ser investigada con mayor profundidad.

Otra conclusión de lo anterior guarda relación con el hecho de que el enquistamiento territorial del conflicto armado colombiano en el noreste y suroeste del país invitase a explorar lógicas de negociación con vistas a superar un conflicto cuya solución militar, sobre la base de lo planteado, cuando menos era bastante difícil. Con las FARC se inició un proceso que desde finales de 2012 ha transcurrido en La Habana y al que se ha llegado, en buena medida, gracias a lo que se conoce como «doble estancamiento doloroso" (mutually hurting stalemate). Es decir, es posible entender que, a tenor de lo propuesto por este trabajo, y que evidencia una posición de hegemonía local profundamente arraigada para el caso de las FARC en los departamentos expuestos, el conflicto armado interno terminara por enquistarse y, por extensión, alcanzar un punto de no retorno, insatisfactorio y sin solución por la vía armada para ninguna de las partes involucradas. Esto, por coincidir con una posición periférica, enquistada, insuficiente para aspirar el poder político por las armas en favor de las FARC, pero también lo suficientemente compleja como para que el Gobierno obtuviese los éxitos militares que protagonizó en el centro y norte del país sobre todo entre 2002 y 2006. Así, fruto de dicho enquistamiento podría entenderse el actual finalizado proceso de paz con las FARC e integrarlo con la voluntad negociadora que lo motivó, hace ahora seis años.

Por todo lo expuesto, los estudios espaciales de la violencia en Colombia aún tienen mucho que aportar, no solo en la interpretación y comprensión en las dinámicas que acompañan a la presencia y activismo de guerrillas y bandas criminales, que es lo que mayormente ha predominado en la literatura (geo)politológica sobre el conflicto armado en Colombia, sino a efectos de entender dónde pueden encontrarse los mayores retos en términos de construcción de paz, cooperación reforzada y transfronteriza o construcción institucional del Estado.

Asimismo, y como se señalaba al inicio, la geografía política termina siendo una disciplina que, como viene sucediendo en los últimos años, debe seguir integrándose con la investigación para la paz y la resolución de conflictos para comprender conflictos como el colombiano, y especialmente por su alto valor agregado a la hora de permitir indagar en cuestiones como las que presenta este artículo, relacionadas con la interacción real de los grupos armados en espacios de disputa y sobre lo cual, pese a todo, sigue siendo necesaria nuevas y mayores investigaciones. Esto es, aportes que, sobre la base de lo planteado, ayuden a encontrar factores descriptivos y explicativos 
desde los que construir nuevos avances en el marco de un objeto de investigación, pese a todo claramente inconcluso y aún por descubrir como es el conflicto armado colombiano.

\section{AGRADECIMIENTOS}

Se agradece expresamente al Observatorio de Derechos Humanos y Derecho Internacional Humanitario, adscrito en su momento a la Vicepresidencia de la República de Colombia, por permitir el acceso a la base de datos sobre el conflicto armado que ha facilitado la realización de esta investigación. Y concretamente, agradecerles a Harvey Suárez y a Luis Gabriel Salas su colaboración.

\section{Referencias}

Agnew, John. 1987. Place and Politics: The Geographical Mediation of State and Society. Londres: Allen and Uwin.

Basedau, Matthias y Jan Pierskalla. 2013. «How Ethnicity Conditions the Effect of Oil and Gas on Civil Conflict: A Spatial Analysis of Africa from 1990 to 2010», Political Geography, 38 (1): 1-11.

Betancourt, Darío. 1991. «Los cinco focos de la mafia colombiana (1968-1988). Elementos para una historia», Revista Folios, 2: 13-30.

Bracanti, Dawn. 2006. «Decentralization: Fueling the Fire or Dampening the Flames of Ethnic Conflict and Secessionism?», International Organization, 60 (3): 651-685.

Buhaug, Halvard y Jan Rød. 2006. «Local Determinants of Africa Civil Wars, 19702001, Political Geography, 25 (3): 315-335. Disponible en: https://doi. org/10.1016/j.polgeo.2006.02.005.

Cederman, Lars Erik., Kristian Gleditsch e Idean Saleyhan. 2013. «Transborder Ethnic Kin and Civil War», International Organization, 67 (2): 389-410. Disponible en: https://doi.org/10.1017/S0020818313000064.

Centro Nacional de Memoria Histórica (CNMH). 2012. Justicia y Paz. Tierras y territorios en las versiones de los paramilitares. Bogotá: $\mathrm{CNMH}$.

Centro Nacional de Memoria Histórica (CNMH). 2013. jBasta Ya! Colombia: Memorias de guerra y dignidad. Bogotá: CNMH.

Cunningham, David., Kristian Gleditsch e Idean Saleyhan. 2009. «It Takes Two: A Dyadic Analysis of Civil War Duration and Outcome», Journal of Conflict Resolution, 53(4):570-593.Disponibleen:https://doi.org/10.1177/0022002709336458.

Echandía, Camilo. 1996. «La amapola en el marco de las economías de ciclo corto en Colombia", Análisis Político, 27: 3-19.

Echandía, Camilo. 1999. Geografia del conflicto armado y las manifestaciones de la violencia en Colombia. Bogotá: Universidad de Los Andes. 
Echandía, Camilo. 2006. Dos décadas de escalamiento del conflicto armado en Colombia 1986-2006. Bogotá: Universidad Externado.

Fals Borda, Orlando, Germán Guzmán y Eduardo Umaña. 1962. La violencia en Colombia. Bogotá: Tercer Mundo.

Ferro, Juan Guillermo y Graciela Uribe. 2002. El orden de la guerra. Las FARC-EP entre la organización y la politica. Bogotá: CEJA.

Forø, Andreas y Halvard Buhaug. 2015. «Insurgency and Inaccessibility», International Studies Review, 17: 6-25. Disponible en: https://doi.org/10.1111/misr.12202.

Galtung, Johan. 2003. Trascender y transformar. Una introducción al trabajo de conflictos. México, D.F.: Transcend-Quimera.

García, Clara Inés y Clara Inés Aramburo. 2011. Geografías de la guerra, el poder y la resistencia. Bogotá: CINEP.

González, Fernán. 2012. Conflicto y territorio en el oriente colombiano. Bogotá: CINEP.

González, Fernán. 2014. Territorio y conflicto en la Costa Caribe. Bogotá: CINEP.

Hegre, Havard, Gudrun Ostby y Clionadh Raleigh. 2009. «Poverty and Civil War Events: A Disaggregated Study of Liberia», Journal of Conflict Resolution, 53 (4): 598-623. Disponible en: https://doi.org/10.1177/0022002709336459.

Horowitz, David. 1985. Ethnic Groups in Conflict. Berkeley: California University Press.

Kaplan, Robert. 2013. La venganza de la geografía. Madrid: RBA.

Linke, Andrew, Frank Witmer y John O’Loughlin. 2012. «Space-Time. Granger Analisys of the War in Iraq: A Study of Coalition and Insurgent Action-Reaction, International Interactions, 4 (38): 402-425. Disponible en: https://doi.org/10.108 0/03050629.2012.696996.

Linke, Andrew y John O’Loughlin. 2015. «Reconceptualizing, Measuring, and Evaluating Distance and Context in the Study of Conflicts: Using Survey Data from the North Caucasus of Russia», International Studies Review, 17: 107-125. Disponible en: https://doi.org/10.1111/misr.12207.

López López, Andrés. 2008. El cártel de los sapos. Bogotá: Planeta.

Medina, Carlos. 2011. Las FARC-EP: flujos y reflujos. La guerra en las regiones. Bogotá: Universidad Nacional.

Mesclier, Évelyne. 1999. Dinámicas socioeconómicas en el espacio colombiano, Bogotá: DANE.

McDoom, Omar. 2014. «Predicting Violence within Genocide: A Model of Elite Competition and Ethnic Segregation from Rwanda», Political Geography, 42 (1): 34-45. Disponible en: https://doi.org/10.1016/j.polgeo.2014.05.006.

O’Loughlin, John. 2012. "Climate Variability and Conflict Risk in East Africa, 19902009", Proceedings of the National Academy of Sciences of the United States of America, 45 (109): 18344-18349. Disponible en: https://doi.org/10.1073/ pnas. 1205130109 .

Observatorio de Derechos Humanos y Derecho Internacional Humanitario (ODHDIH). (s.f.) Sintesis de la violencia y la confrontación armada en Colombia, 19982012 y 2015. Bogotá: Vicepresidencia de la República. 
Observatorio Geopolítico de las Drogas. 1996. Informe Anual. Geopolitica Mundial de las Drogas. París: OGD.

Pattie, Charles y Ron Johnston. 2000. «People Who Talk Together Vote Together: An Exploration of Contextual Effects in Great Britain", Annals of the Association of American Geographers, 90 (1): 41-66. Disponible en: https://doi. org/10.1111/0004-5608.00183.

Raleigh, Clionadh y Havard Hegre. 2009. «Population Size, Concentration and Civil War: A Geographically Dissagregated Analysis», Political Geography, 28 (4): 224238. Disponible en: https://doi.org/10.1016/j.polgeo.2009.05.007.

Ramírez, William. 2001. «Colonización armada, poder local y territorialización privada", Journal of Iberian and Latinoamerican Research, 7 (2): 63-81. Disponible en: https://doi.org/10.1080/13260219.2001.10430031.

Reyes, Alejandro y Jesús Antonio Bejarano. 1988. «Conflictos agrarios y luchas armadas en la Colombia contemporánea", Análisis Politico, 5: 6-27.

Reyes, Alejandro. 1993. Geografia de la violencia en Colombia. Informe de investigación. Bogotá: IEPRI.

Reyes, Alejandro. 2009. Guerreros y campesinos. El despojo de la tierra en Colombia. Bogotá: Norma.

Ríos, Jerónimo. 2016. «La periferialización del conflicto armado colombiano, 20022014», en Geopolitica(s). Revista sobre Estudios de Espacio y Poder, 7 (2): 251-275.

Ríos, Jerónimo. 2017. Breve historia del conflicto armado en Colombia. Madrid: La Catarata.

Rodríguez Cuadros, José Darío. 2015. Génesis, actores y dinámicas de la violencia política en el Pacifico nariñense. Bogotá: CINEP.

Salas, Luis. 2010. "Corredores y territorios del conflicto armado colombiano: una prioridad en la geopolítica de los actores armados", Perspectiva Geográfica, 15: 9-36.

Salas, Luis. 2015. «Lógicas territoriales y relaciones de poder en el espacio de los actores armados: un aporte desde la geografía política al estudio de la violencia y el conflicto armado en Colombia, 1990-2012», Cuadernos de Geografía, 24 (1): 157-172.

Saleyhan, Idean. 2009. Rebels Without Borders: State Boundaries, Transnational Opposition and Civil Conflict. Nueva York: Cornell University Press. Disponible en: https://doi.org/10.7591/9780801459214.

Schutte, Sebastian y Karsten Donnay. 2014. «Matched wake analysis: Finding causal relationships in spatiotemporal event data», Political Geography, 41 (1): 1-10. Disponible en: https://doi.org/10.1016/j.polgeo.2014.03.001.

Schutte, Sebastian. 2015. «Geography, Outcome and Casualties: A Unified Model of Insurgency», Journal of Conflict Resolution, 59 (6): 1101-1128. Disponible en: https://doi.org/10.1177/0022002713520534.

Snyder, Richard. 2006. «Does lootable wealth breed disorder?», Comparative Political Studies, 8(39):943-968.Disponibleen:https://doi.org/10.1177/0010414006288724.

Taylor, Peter y Colin Flint. 2002. Geografía Politica: Sistema-mundo, Estado-nación y localidad. Madrid: Trama. 
Torres, María Clara. 2011. Estado y coca en la frontera colombiana. El caso de Putumayo. Bogotá: CINEP.

Trejos, Luis Fernando. 2016. «Hipótesis explicativas de la derrota estratégica de la insurgencia armada en el Caribe colombiano: los casos de las FARC-EP y el ELN», Revista de Derecho, 45: 346-377.

United Nations Office on Drugs and Crime (UNODC). 2016. Colombia. Monitoreo de cultivos de coca 2015. Viena: Naciones Unidas.

Vargas, Roberto. 1994. "La venganza de la marimba empezó aquí», en VV. AA, La verdad del 93: paz, derechos humanos y violencia. Bogotá: CINEP.

Vásquez, Teófilo. 2011. Una vieja guerra en un nuevo contexto. Conflicto y territorio en el sur de Colombia. Bogotá: CINEP.

Vélez, María. 2001. «FARC-ELN: evolución y expansión territorial», Desarrollo y Sociedad, 47: 151-225.

Woodhouse, Tom., Hugh Miall., Oliver Ramsbotham y Christopher Miall. 2015. The Contemporary Conflict Resolution Reader. Cambridge: Polity Press.

Presentado para evaluación: 4 de diciembre de 2016.

Aceptado para publicación: 15 de junio de 2017.

\section{JERÓNIMO RÍOS}

jriossie@universidadean.edu.co

Doctor en Ciencias Políticas por la Universidad Complutense de Madrid. Es actualmente profesor asociado de la Facultad de Administración, Finanzas y Ciencias Económicas de la Universidad EAN (Colombia) y asesor de la Organización de Estados Iberomericanos, OEI Colombia. 